\title{
Bedside clinicians retain nurses through turnover analysis and best practices
}

\author{
Nina Hawthorne-Spears,' Mary Shepherd \\ Houston Methodist Hospital-Texas Medical Center, Houston, Texas, USA
}

Received: February 25, 2019

Accepted: April 21, 2019

Online Published: August 21, 2019

DOI: $10.5430 /$ jnep.v9n12p27

URL: https://doi.org/10.5430/jnep.v9n12p27

\begin{abstract}
The nursing shortage is projected to grow to well over 500,000 by 2020 . Health care organizations are faced with increasing vacancies, mandating that strategic initiatives be developed to address the imperative of retaining their registered nurses (RNs). The implications for reducing RN turnover include improved safety and quality outcomes for patients. RN turnover also has financial implications. The average annual hospital cost of RN turnover is between $\$ 5.2$ and $\$ 8.1$ million dollars. Houston Methodist Hospital in the Texas Medical Center is a large, 1,200-bed metropolitan facility that employs over 3,000 nurses. By using shared governance to engage bedside clinicians and the ADKAR change model, nurse leaders were able to reduce organizational RN turnover from $16.39 \%$ to $10.57 \%$, outperforming the national average and the American Nurses Credentialing Center's benchmark for Magnet facilities with greater than or equal to 700 beds. This article will discuss the role of nurse leaders in creating a culture of retention, methods that were implemented at Houston Methodist Hospital to engage and empower beside clinicians to assume a lead role in reducing $\mathrm{RN}$ turnover, and the best practices discovered and implemented by bedside clinicians to improve $\mathrm{RN}$ turnover.
\end{abstract}

Key Words: Bedside clinicians, Registered nurse turnover, Nurse leader, Engagement

\section{INTRODUCTION}

Leaders are charged with engaging and empowering both nurses and interprofessional team members to be actively involved in accomplishing safety, quality, financial, patient, and nurse satisfaction outcomes. Prosci's Change Management Benchmarking Study, which included 650 participants from 62 countries, ranked the challenges that affect the success of a change. ${ }^{[1]}$ The study identified the first and second greatest obstacles inhibiting change as "ineffective change management sponsorship from senior leaders" and "insufficient change management resourcing" ${ }^{[2]}$ Recognizing this, nursing leaders at Houston Methodist Hospital (HMH) chose to use the ADKAR change model and shared governance structure to guide and influence Magnet champions (MCs) along a journey to improve the nursing turnover rate.

\section{BACKGROUND AND SIGNIFICANCE}

$\mathrm{HMH}$ is a $1200-$ licensed-bed, full-service, acute-care, nonprofit, academic Magnet-recognized hospital. The hospital resides in the Texas Medical Center, the largest medical complex in the world, with 21 other hospitals, including several Magnet-designated hospitals, all of which compete for the same pool of nurses. ${ }^{[3]} \mathrm{HMH}$ employs over 3000 RNs. Nurse satisfaction is a hospital priority.

The United States is on the verge of a staffing crisis, and Texas, the second most populous state, is experiencing a

\footnotetext{
* Correspondence: Nina Hawthorne-Spears; Email: NRHawthorne@ houstonmethodist.org; Address: Houston Methodist Hospital-Texas Medical Center, Houston, Texas, USA.
} 
significant nursing shortage-the worst in a decade. The American Nurses Association projects that by 2022, 1.1 million nurses will be needed to backfill the vacancies left by retiring nurses and to meet the needs of the growing patient population over the age of $65 .{ }^{[4]}$ Eighty-one percent of this growing population has multiple chronic conditions, which further compounds the need for registered nurses (RNs). ${ }^{[5]}$ The Health Resources and Services Administration Health Workforce projects that the supply of nurses needed in Texas in 2030 will be 253, 400 compared with a demand of 269 , 300 nurses, resulting in a shortfall of 15,900 , or $5.9 \% .^{[6]}$

Nationally, RN turnover is estimated to be $16.5 \%$. ${ }^{[5]}$ In 2016 , the state of Texas employed 224,780 RNs; the 2016 regional average $\mathrm{RN}$ turnover rate was $21.9 \%$ and the vacancy rate was $11.5 \% .^{[7]}$ The average time to recruit an experienced nurse ranges from 54 to 109 days, with turnover costs ranging from $\$ 44,380$ to $\$ 63,400 .{ }^{[5]}$ Direct recruitment costs are estimated conservatively to be $\$ 10,000$ per nurse. ${ }^{[8]}$

Nurse engagement is used to describe nurses who are committed and satisfied with their job. ${ }^{[9]}$ Engagement is directly linked with patient safety, quality, and the patient experience and is associated with nurse turnover. ${ }^{[10]}$ Nurse retention is a top priority that affects a hospital's performance and profitability in numerous ways and takes a toll on bedside clinicians, further contributing to turnover and diminishing staffing levels. The quality of care may suffer, and dissatisfied patients may elect to go elsewhere; staffing costs may rise for use of agency nurses, and sign-on bonuses to fill vacant positions and cover absenteeism; and organizations may see more accidents. ${ }^{[11]}$ The Institute of Medicine Committee on the Adequacy of Nursing Staffing in Hospitals and Nursing Homes reviewed the link between work-related injuries and staffing levels. They found conclusive evidence of a strong link between nurse staffing and back injuries. ${ }^{[12]}$ Additionally, the Centers for Disease Control and Prevention noted that "sharps injuries are typically the result of using dangerous equipment in a fast-paced, stressful, and understaffed environment", which can produce fatigue. ${ }^{[13]}$

Considering the cost and time it takes to recruit a nurse, it is imperative that nursing leaders implement strategies to engage nurses and increase retention, i.e., the proportion of nurses who remain employed. By understanding the reasons that nurses leave an organization and the impact turnover has on a hospital's ability to perform and implement its strategic goals, employers can develop targeted actions to reduce RN turnover and increase retention. Partnering with human resources to routinely measure and understand $\mathrm{RN}$ turnover and those factors both controlled and not controlled by the employer is the first step in retaining employees. ${ }^{[14]}$
Engagement requires change and transformational leadership to build trust to achieve a common purpose: "Trust (organizationally, managerially and collegiality) and autonomy are the antecedents of work engagement."[15] Transformational leaders give meaning to the work done by employees by clarifying the work needed to support the organization's mission and values and provide the tools to accomplish a common purpose. They build relationships that enhance psychological well-being and commitment, thus positively influencing an individual's intent to leave the organization. ${ }^{[16]}$

Change requires that several levers be implemented in synchronization with a shared agenda. The Advisory Board's 2014 "National Prescription for Nurse Engagement" identified several dimensions, later summarized by Oshiro in $2016,{ }^{[17]}$ that should be considered to engage nurses:

- Executive Actions: leaders must enact their role in accordance with the mission and vision of the organization and lead by example.

- Stress and Burnout: Nurses are the primary caregivers in a hospital setting, i.e., the reason patients must be hospitalized is for nursing care. Nurses are expected to lead the interprofessional team, coordinate and communicate the patient's plan of care, implement federal mandates related to the transition to value-based care, lead quality initiatives, and implement new protocols and strategies to improve the quality of care. By empowering nurses to implement their role, while preventing burnout, greater success can be achieved.

- Staff Input: nurses need to be involved in developing new initiatives in which they have a role. Data is a key component in understanding the need for change.

- Recognition: respect and recognition are meaningful ways to acknowledge the contributions that nurses make. Recognition in a public forum is particularly meaningful. A simple note of gratitude also conveys acknowledgement and gratitude for a job well done.

- Professional Development: training and development is essential in giving nurses the skills and knowledge to perform their work and implement their roles as leaders. Professional development also fosters engagement by boosting nurses' confidence in their ability to provide optimal care and guide the interprofessional team.

A direct link between empowerment and engagement is prevalent in the literature. When employees are engaged, they are more productive and apt to perform those behaviors that ground an organization's success. According to Maslach et al., ${ }^{[18]}$ engagement is the opposite of burnout. BabcockRoberson and Strickland ${ }^{[19]}$ identified a mediation model 
that encompasses six interrelated job factors that promote engagement as follows: workload, control, reward, community, fairness, and values.

Shared governance, a professional practice model, is built on a foundation of clinician autonomy. ${ }^{[20]}$ Autonomy includes the concepts of self-governance, decision-making, competency, critical reflection, and self-control. ${ }^{[21]}$ The structures inherent in collaborative governance place the authority, responsibility, and accountability for patient care and other outcomes on the practicing clinician and give meaning to the concept of empowerment. Structural empowerment promotes access to resources, information, and leadership support; opportunities for professional growth; and RN satisfaction. ${ }^{[22]}$

Structural Empowerment, a Magnet Domain, envelops shared governance and is a prerequisite of the American Nurses Credentialing Center, which administers the Magnet Recognition Program. HMH achieved Magnet recognition in 2002 and is currently on its journey toward a fifth designation. At HMH, shared governance is a way of life; it's how nurses practice. The hospital's Shared Governance Model for Leadership and Professional Practice was implemented in 2000. In 2016, the RN turnover rate rose to $16.39 \%$. The hospital had several new managers with little to no experience with shared governance, which disrupted the culture and affected the RN turnover rate. Naturally, nursing leaders jumped into gear and used the structures and processes inherent in a shared governance model to engage $120 \mathrm{MCs}$, who represented 33 nursing units, to lead the way in reducing the RN turnover rate. The hospital's official change management model, ADKAR (Awareness, Desire, Knowledge, Ability, and Reinforcement), was used to drive this enhancement. ${ }^{[23]}$

\section{ADKAR CHANGE MODEL AND SHARED GOVERNANCE}

ADKAR is an acronym for the change model that was used to work with MCs to improve RN turnover at HMH. The acronym stands for Awareness, Desire, Knowledge, Ability, and Reinforcement. The actions taken by nursing leaders are summarized and aligned with the steps of the ADKAR model as depicted in Table 1.

Table 1. ADKAR Change Management Principles and Nursing Leadership Strategies

\begin{tabular}{|c|c|}
\hline ADKAR Principle & Nursing Leadership Strategies \\
\hline Awareness & $\begin{array}{l}\text { - Created a shared vision } \\
\text { - Senior outcome analyst presented nursing dashboard data (nurse-sensitive indicators) }\end{array}$ \\
\hline Desire & $\begin{array}{l}\text { - Seven Magnet champion (MC) teams were formed } \\
\text { - MCs were educated on SMART goal development } \\
\text { - MCs developed a SMART goal to reduce RN turnover } \\
\text { - Distributed literature and educated MCs on completing a SWOT analysis } \\
\text { - Facilitated SWOT analysis } \\
\text { - Facilitated PICK chart exercise } \\
\text { - Chief nurse executive and senior vice president demonstrated support for initiative by attending MC meetings }\end{array}$ \\
\hline Knowledge & $\begin{array}{l}\text { - Human resources director attended MC meeting and presented RN turnover, RN satisfaction, and post-employee } \\
\text { survey data } \\
\text { - MCs were asked to query unit staff to obtain information on why nurses leave and strategies preferred to promote } \\
\text { staff retention } \\
\text { - MCs were assigned to review nurse retention literature for best practices and summarize findings } \\
\text { - Senior MCs were assigned to team to serve as a resource and provide support during unit-based meetings } \\
\text { - Seven MC teams presented nurse retention best practices and implementation plans } \\
\text { - Senior MCs consolidated nurse retention best practices and plans }\end{array}$ \\
\hline Ability & $\begin{array}{l}\text { - Senior MCs developed and distributed a tool that included nurse retention best practices to MCs for integration } \\
\text { on their unit } \\
\text { - MCs were educated on how to engage unit-based shared governance councils } \\
\text { - Continued monthly review of RN turnover data with MCs } \\
\text { - MC teams presented monthly progress on the implementation of their plans to reduce RN turnover }\end{array}$ \\
\hline Reinforcement & $\begin{array}{l}\text { - Publicly recognized MCs with the most improved RN turnover rate } \\
\text { - Quarterly award to team with lowest RN turnover rate } \\
\text { - MCs presented project at Houston Methodist Regional Shared Governance Conference } \\
\text { - MC presented poster at national ANCC Magnet Conference } \\
\text { - Offsite team-building activity held } \\
\text { - End of year celebration } \\
\text { - Ongoing dissemination of RN turnover rate to MCs }\end{array}$ \\
\hline
\end{tabular}

Note. ANCC = American Nurses Credentialing Center; PICK = possible, implement, challenge, and kill; RN = registered nurse; SMART = specific, measureable, attainable, relevant, and timely; SWOT = strengths, weaknesses, opportunities, and threats. 


\subsection{Awareness}

The ADKAR model elements are sequential, with the first being awareness. ${ }^{[24]}$ This step is integral to ensuring that all those involved in the change are conscious and aware of the need for a change. ${ }^{[24]}$ Nursing leaders at HMH were committed to reducing RN turnover and recognized the significance of engaging MCs in this change initiative. MCs are composed of bedside RN clinicians, educators, radiology technologist, pharmacists, physical therapists, case managers, building services personnel, and an outcome specialist.

Awareness began by creating a shared vision. A shared vision is aligned with the shared governance principles of inclusiveness, integrity, and professionalism, which lead to mutual understanding and efficient collaboration among teams. ${ }^{[25]}$ To create this vision, MCs were simply asked, What is your vision of the contribution that the role of a MC should bring
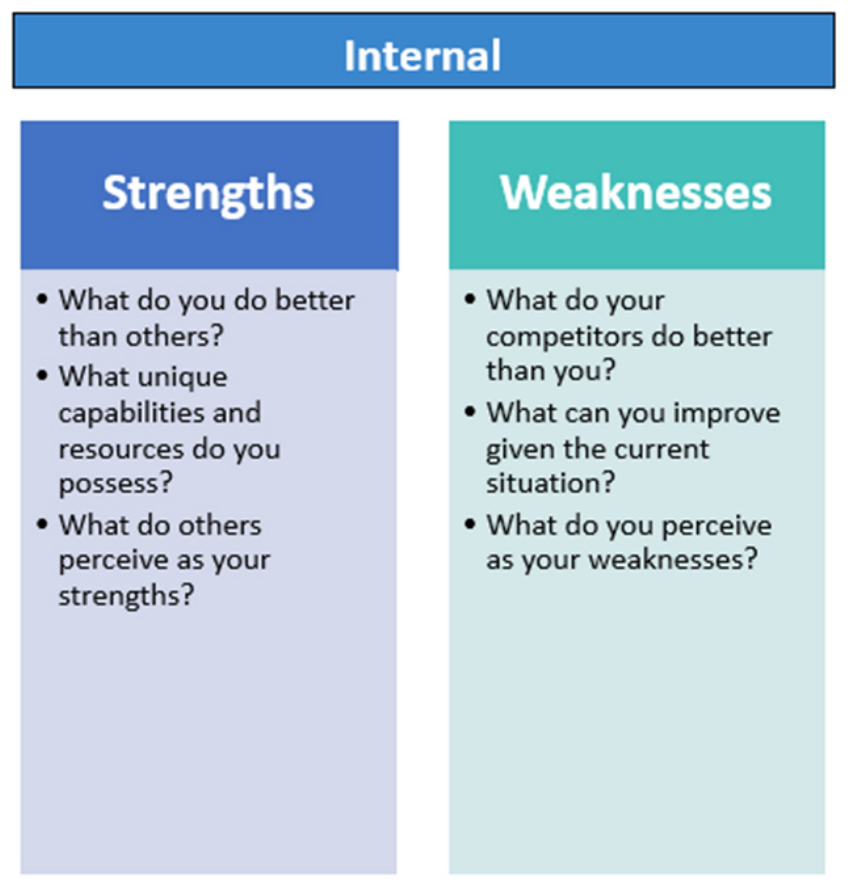

Figure 1. SWOT Analysis Guide ${ }^{[26]}$

The SWOT analysis was helpful in assessing the internal and external environments, reviewing RN turnover and other data, identifying opportunities, and determining and understanding those factors that could affect the success of this project. The analysis also enabled MCs to identify the resources needed to plan, implement, and sustain the project. MCs had a vested interest in this project, because nurse turnover directly affects their workload. As key stakeholders, MCs felt that it was in their best interest to be directly involved in this project, and they agreed to drive this project in their respective departments, with the support of a senior MC. ${ }^{[27]}$ to HMH? Many thoughts were verbalized and several themes emerged. The final vision established was "Leading the World of Healthcare in an Innovative, Collaborative and Caring Environment through Excellence in Patient and Family Centered Care, Advanced Education, Research, and Dissemination of Best Practices."

Once the vision was formulated, MCs were guided by senior MCs through a SWOT analysis exercise to determine which opportunities were essential in creating a workplace aligned with the new shared vision (see Figure 1). SWOT stands for Strengths, Weaknesses, Opportunities, and Threats. ${ }^{[26]}$ The best results of a SWOT analysis are achieved with a group of people holding various perspectives and stakes in accomplishing the goal. ${ }^{[26]}$ MCs can be described as just that.

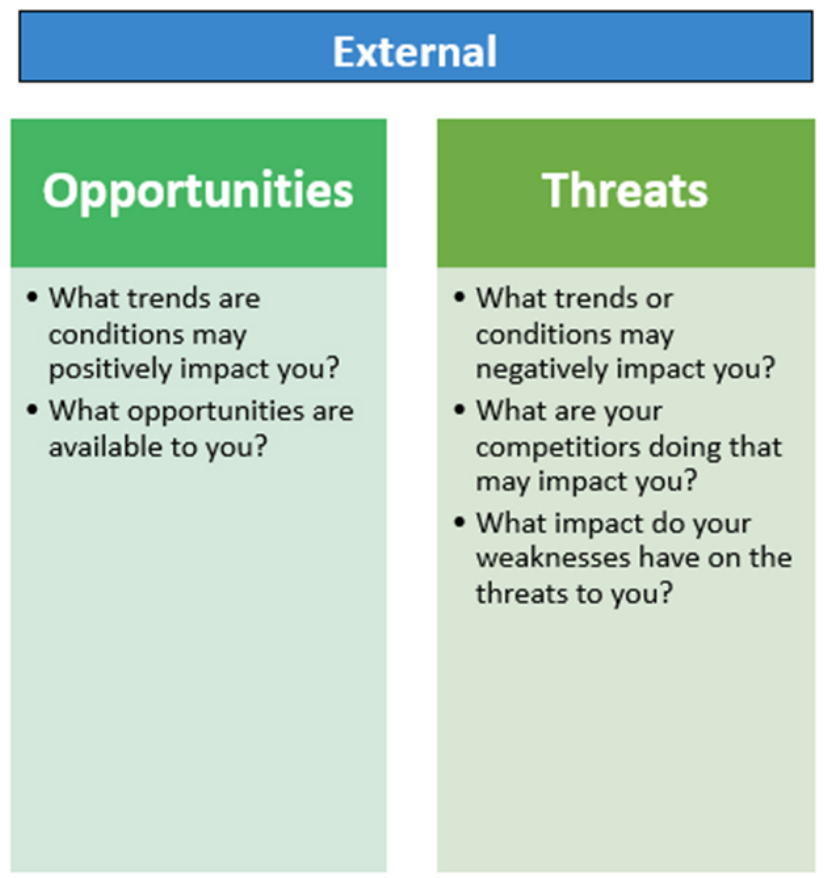

Historically, involving MCs in identifying opportunities and making decisions that directly impact their work has yielded better results and is consistent with the hospital's shared governance professional practice model, which places the authority, responsibility, and accountability for patient care and other outcomes on the practicing clinician. Active participation in this manner not only engages and empowers MCs, but also increases their job satisfaction. Laschinger et al. $^{[28]}$ found that a significant predictor of job satisfaction and retention is an empowering practice environment. Increased satisfaction, commitment to the organization, and 
intent to leave the organization are all linked to higher empowerment. ${ }^{[27]}$

\subsection{Desire}

The process of completing the SWOT not only enhanced the MCs' awareness of the need to improve the $\mathrm{RN}$ turnover rate but also bridged into the desire step of the ADKAR change model. The desire step states that the person participating in the change must have the want or desire to engage and fully support the change. ${ }^{[23]}$ Practice areas identified by MCs through the SWOT analysis included improving RN turnover. This approach led to increased buy-in and "desire" and was consistent with a shared decision-making model. ${ }^{[26]}$

Following receipt of input from the MCs, the next step was to categorize and determine the best ideas that would yield the biggest payoff for the organization in reducing $\mathrm{RN}$ turnover and which could be easily implemented. This was accomplished through the use of a PICK chart (see Figure 2). PICK stands for possible, implement, challenge, and kill. PICK is a method that is most often utilized in Six Sigma, a management philosophy in Lean. ${ }^{[2]}$ It categorizes ideas as follows:

- Possible - an initiative that is achievable but has low reward to the organization.

- Implement - an initiative that is achievable and has a high reward to the organization.

- Challenge - an initiative that is hard to put into place and is difficult to determine the reward to the organization.

- Kill - an initiative that is hard to put into place and has a low reward to the organization.

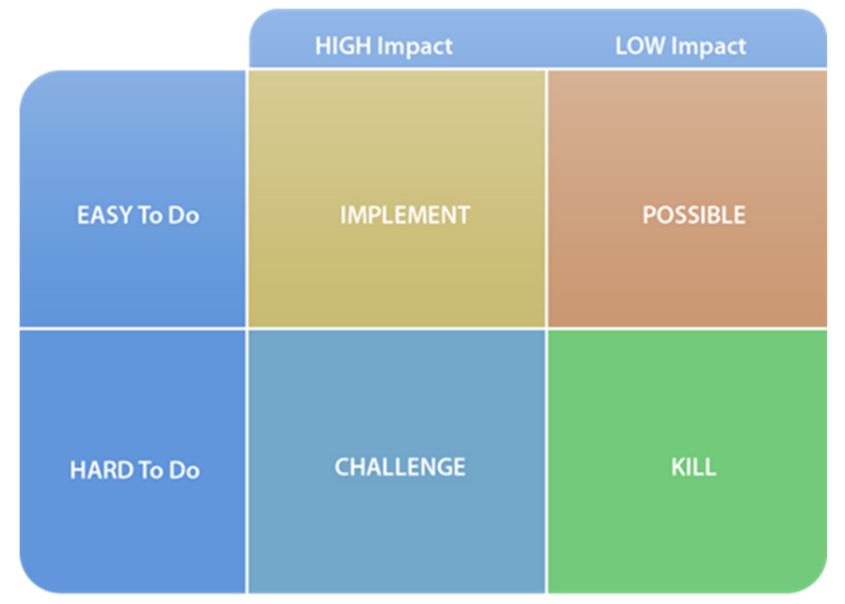

Figure 2. PICK chart

This exercise enabled the MCs to assimilate and quickly categorize their ideas and place them in the appropriate location on the PICK chart. When faced with multiple alternatives, the MCs used the PICK chart to visually manage and display the ideas. This facilitated decision-making and empowered the MCs to prioritize and determine which option they perceived to be most effective and which one they could "own" to reduce $\mathrm{RN}$ turnover. This enhanced movement along the continuum of the ADKAR model.

In the next step, the MCs developed a SMART goal to reduce RN turnover. The purpose of a SMART goal is to add structure, tractability, and clear milestones. SMART refers to 5 components of a goal: specific, measureable, attainable, relevant, and timely. ${ }^{[28]}$

\subsection{Knowledge and awareness}

The next two steps in ADKAR are knowledge and ability. ${ }^{[23]}$ Knowledge refers to the ability to know how to change and involves coaching and educating those participating in the change. ${ }^{[23]}$ Ability is being able to implement the change appropriately. ${ }^{[23]}$ Nursing leaders at $\mathrm{HMH}$ recognized that both of these change management principles were integral to the success of the MCs. Often, those who are not in a leadership position feel powerless when it comes to enacting change that affects the organization; however, being equipped with the right knowledge and ability increases an individual's confidence in participating in these changes.

Nursing leaders facilitated the knowledge and ability of the MCs through the following:

(1) Invited the director of Human Resources to a MC meeting to review the methodology for calculating the $\mathrm{RN}$ turnover rate, educated the MCs in differentiating between controllable (related to environmental factors under the control of the employer, e.g., pay status, advancement) and uncontrollable turnover (not related to environmental factors under the control of the employer, e.g., relocation, retirement), and provided RN satisfaction data and information from post-employee survey calls.

(2) Instructed MCs to query unit nurses to obtain information on why nurses leave their unit and obtain feedback on strategies to promote retention.

(3) Obtained RN turnover data from human resources and shared it at monthly MC meetings.

(4) Assigned MCs to review the literature for best practices that have been shown to positively impact RN turnover. (Note. At the beginning of the year, MCs were divided into 7 self-selected teams. Each team was asked to select a leader (i.e., someone who would facilitate the work by reinforcing the roles and tasks of each member and then summarize and present their plan and progress at monthly MC meetings). This structure facilitated communication and enabled each 
team to leverage the skills and competencies of individual members, while holding each other accountable. Each team presented best practices discovered to the larger MC group and voted on which team presented the best practices. Following these presentations, senior MCs consolidated the proposed interventions and drafted a MC RN retention checklist (see Table 2).)
(5) Held discussions at monthly MC meetings of strategies that promoted buy-in and provided an ongoing opportunity to guide MCs on how to best engage their unit-based shared governance councils.

(6) Assigned a senior MC to each team to serve as a resource and provide support during unit-based meetings.

Table 2. Houston Methodist Hospital Magnet champion Best Practices for Nurse Retention

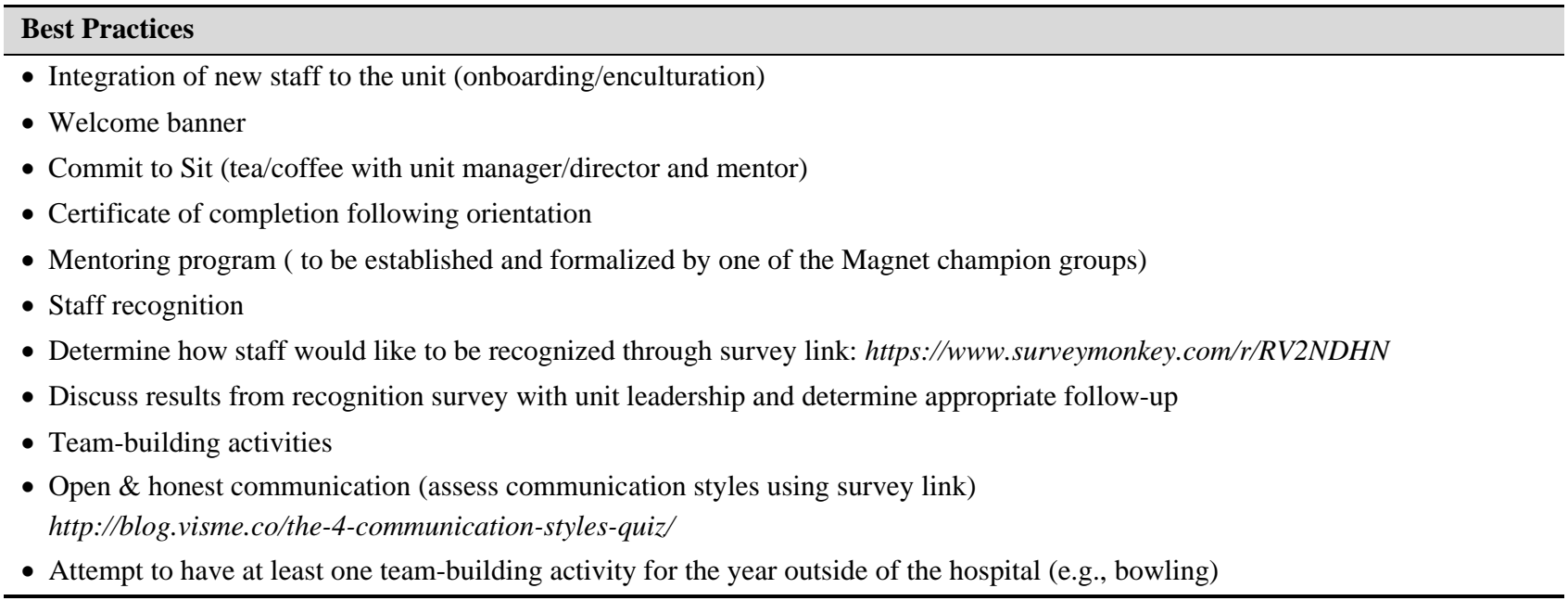

\subsection{Reinforcement}

Reinforcement is the last step of the ADKAR change model. ${ }^{[23]}$ This step ensures that the change is sustained. It involves continuous monitoring of the outcome of the initiative. ${ }^{[23]}$ It was imperative that nursing leaders provide $\mathrm{RN}$ turnover data on a regular basis to show MCs their progress toward the goal of improving the RN turnover rate. The " $R$ " conveys the need for rewards. Rewards lets those who are a part of a team know that nursing leaders are aware of their success in accomplishing the change and have a desire to acknowledge them in a tangible way. MCs were recognized and rewarded for their leadership and success in accomplishing the goal of implementing strategies to improve $\mathrm{RN}$ turnover throughout the year. Quarterly, the team with the most improved RN turnover rate received a MC trophy that could be displayed on their unit. Additionally, the entire team's success was recognized at the end of the year with a celebration held during the last meeting. The celebration included a themed party, which included food, fun activities, and certificates of recognition for individual contributions.

\section{Evaluation AND OUTCOMES}

MCs successfully met the organizational goal of reducing RN turnover. Between January 2017 and September 2017, $\mathrm{RN}$ turnover at $\mathrm{HMH}$ was reduced by $5.82 \%$ (from $16.39 \%$ to $10.57 \%$.) HMH's RN turnover rate at the time of project completion was lower than the national average (17.2\%) and was lower than the American Nurses Credentialing Center's benchmark for facilities with greater than or equal to 700 beds $(11.39 \%)$.

Nursing leaders inspired this MC initiative not only with the intent of improving RN turnover, but also with a goal of encouraging bedside clinicians to complete a project aligned with nursing's strategic plan. HMH MCs can now state that they have participated in an evidence-based practice project that supports the organization's goals and can guide their unit-based teams along the same path of success.

As leaders, it was an invigorating experience to lead a team of bedside clinicians along the path of success. Employees are only as good as the tools with which they have to work. This process demonstrated that individuals in non-leadership positions in organizations who are equipped with the resources and support needed to be successful can drive change that supports an organization's strategic goals. As a Magnet facility, HMH's Professional Practice Model establishes the staff nurse as the key driver in achieving outcomes. This was a prime example. 


\section{IMPLICATIONS FOR PRACTICE}

$\mathrm{RN}$ turnover is a concern for both economic and noneconomic reasons. For each percentage of annual RN turnover, a hospital is estimated to lose between $\$ 300,000$ and $\$ 379,500 .{ }^{[30]}$ When experienced nurses leave an organization, they take with them the knowledge and skills that are essential in providing safe, quality care, negatively affecting the psychological well-being of the nurses who remain employed, and the organization's effectiveness and costs. Nurses value a positive work environment, autonomy, lead- ership support, and opportunities that promote professional growth and job satisfaction. The role of transformational leaders is to build community around a common purpose through specific actions. Shared governance offers a vehicle to engage nurses and fosters team collaboration as peers challenge each other to achieve a common goal. Reinforcement comes when leaders recognize and reward employees who add value to the organization.

\section{CONFLicts OF InTEREST Disclosure}

\section{REFERENCES}

[1] PROCSI Change Management. Fort Collins, CO: Prosci; c2012 [cited 2018 Jan]. Available from: https://www.prosci.com/about

[2] Bareil C. Two paradigms about resistance to change. Organization Development Journal. 2013 Fall; 31(3): 59-71.

[3] These 10 facts about the Texas Medical Center will make you want to work there. Pulse Staffing; 2018 Feb 22 [cited 2018 Apr 1]. Available from: http://www.pulsestaffing.com/10-fac ts-texas-medical-center-will-make-want-work

[4] Workforce. American Nurses Association [cited 2018 May 21]. Available from: https://www.nursingworld.org/practice-pol icy/workforce

[5] The nursing shortage and how it will impact patient care. Bradley University [cited 2018 Apr 20]. Available from: https://online degrees.bradley.edu/resources/infographics/the-nur sing-shortage-and-how-it-will-impact-patient-care/

[6] US Department of Health and Human Services, Health Resources and Services Administration, Bureau of Health Workforce, National Center for Health Workforce Analysis. Supply and Demand Projections of the Nursing Workforce: 2014-2030. Rockville (MD): US DHHS; c2017. Available from: https://bhw.hrsa.gov/sites/default/files/bhw/nchwa /projections/NCHWA_HRSA_Nursing_Report.pdf

[7] Texas Center for Nursing Workforce Studies. Hospital Nurse Staffing Study: Vacancy and Turnover. Austin (TX): Texas Department of State Health Services; c2016. Available from: http://www.dshs .texas.gov/chs/cnws/

[8] Solving the nursing shortage: the cost of failure. American Federation of State, County and Municipal Employees [cited 2018 Apr]. Available from: https://www afscme.org/news/publicatio ns/health-care/solving-the-nursing-shortage

[9] Dempsey C, Reilly B. Nurse engagement: what are the contributing factors for success? Online Journal of Issues in Nursing. 2016; 21(1).

[10] Jones C, Gates M. The costs and benefits of nurse turnover: a business case for nurse retention. Online Journal of Issues in Nursing. 2007; 12(3)

[11] Hunt S. Nursing Turnover: Costs, Causes \& Solutions. Success Factors for Healthcare. 2009. [cited 2018 Jan]. Available from: https://www.pdffiller.com/102074040-LHHS-081312-N ursingTurnoverpdf-Nursing-Turnover-Costs-Causes-a mpampamp-Solutions-

[12] Institute of Medicine (US) Committee on the Adequacy of Nursing Staff in Hospitals and Nursing Homes, Wunderlich GS, Sloan F, Davis CK, eds. Nursing Staff in Hospitals and Nursing Homes: Is
It Adequate? Washington (DC): National Academies Press; c1996. Available from: https://www.ncbi.nlm.nih.gov/books/NBK 232675/

[13] Stop Sticks Campaign: Campaign User's Guide and Resources [Internet]. Centers for Disease Control and Prevention; revised 2013 Jun 26 [cited 2018 Jan]. Available from: https ://www. cdc .gov/ niosh/stopsticks/default.html

[14] Employee turnover and retention [Internet]. Chartered Institute of Personnel and Development; 2018 Jul 18 [cited 2018 Jul]. Available from: https://www.cipd.co.uk/knowledge/strategy/reso urcing/turnover-retention-factsheet

[15] Bargagliotti L. Work engagement in nursing: a concept analysis J Advanced Nursing. 2012; 68(6): 1414-1428. PMid:22044047 https://doi.org/10.1111/j.1365-2648.2011.05859.x

[16] Burnetto Y, Teo S. Retention, burnout and the future of nursing. J Advanced Nursing. 2013 Dec; 69(12). PMid:24236950 https: //doi.org/10.1111/jan.12309

[17] Oshiro B. The best way hospitals can engage physicians, nurses and staff. Health Catalyst Insights [cited 2018 Jan]. Available from: https://www.healthcatalyst. com/the-best-way-h ospitals-engage-physicians-nurses-and-staff

[18] Maslach C, Leiter M. Burnout. Encyclopedia of Stress, 2nd ed. New York: Elsevier; 2007; 358-362.

[19] Babcock-Roberson M, Strickland O. The relationship between charismatic leadership, work engagement and organizational citizenship behaviors. J Psychol. 2010 May-June; 144(3): 313-26. PMid:20461933 https://doi.org/10.1080/00223981003648336

[20] Anthony M. Shared governance models: the theory, practice and evidence. Online Journal of Issues in Nursing. 2004; 9(1). Available from: http://ojin.nursingworld.org/MainMenuCategori es/ANAMarketplace/ANAPeriodicals/OJIN/TableofConte nts/Volume92004/No1Jan04/SharedGovernanceModels.ht $\mathrm{ml}$

[21] Ballou K. A concept analysis of autonomy. J Prof Nurs. 1998; 14(2): 102-110. https://doi.org/10.1016/S8755-7223(98 ) $80038-0$

[22] Orgambidez-Ramos A, Borrego-Ales Y. Empowering employees: structural empowerment as antecedent of job satisfaction in university settings. Psychological Thought. 2014; 7(1). https ://doi.or g/10.5964/psyct.v7i1.88

[23] Haiti JM. ADKAR: A Model for Change in Business, Government and our Community. Loveland (CO): Procsi; 2006. 
[24] Mulder P. ADKAR model of change. Toolshero; 2013 [cited 2018 May 15]. Available from: https://www.toolshero.com/chan ge-management/adkar-model/

[25] McGowan B, Goode D, Manley K. Facilitating the development of a shared purpose in a university department: The first stage towards developing a culture of shared governance. Int Pract Dev J. 2016 Nov; 6(2): 8. https://doi.org/10.19043/ipdj.62.008

[26] Enwereuzor IK, Ugwu LI, Eze OA. How transformational leadership influences work engagement among nurses: does person-job fit matter? West J Nurs Res. 2018; 40(3): 346-366. PMid:27920346 https://doi.org/10.1177/0193945916682449

[27] Bull JW, Jobstvogt N, Bohnke-Henrichs C, et al. Strengths, weaknesses, opportunities and threats: a SWOT analysis of the ecosystem services framework. Ecosystem Serv. 2016; 17: 99-111. https: //doi.org/10.1016/j. ecoser. 2015.11.012

[28] Laschinger HKS, Leiter M, Day A, et al. Workplace empowerment, incivility, and burnout: impact on staff nurse recruitment and retention outcomes. J Nurs Manag. 2009; 17(3): 302-311. PMid:19426367 https://doi.org/10.1111/j.1365-2834.2009.00999.x

[29] Mind Tools Content Team. SMART goals: how to make your goals achievable. Mind Tools [cited 2018 Jan]. Available from: https: //www.mindtools.com/pages/article/smart-goals.htm

[30] Sharp L. The importance of strong leadership [Internet]. European Oncology Nursing Society Magazine. Spring/Summer 2017 [cited 2018 Jan]. Available from: http://www . eonsmagazine.eu/springsummer-2017/im portance-strong-leadership-retaining-nurses 